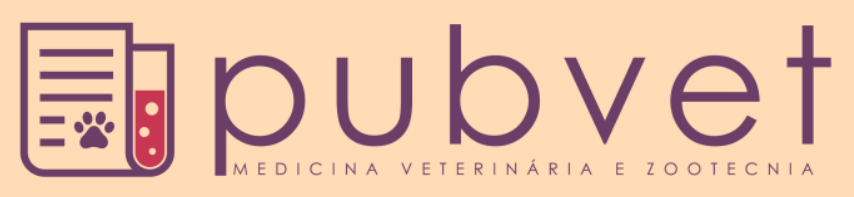

https://doi.org/10.31533/pubvet.v12n8a154.1-6

\title{
Dermatite atópica canina: Estudo de caso
}

\author{
Breno Henrique Alves ${ }^{1 *}$, José Antônio Viana ${ }^{2}$, Matheus Hernandes Leira ${ }^{3}$, Natália \\ do Prado Alves e Rodrigues ${ }^{4}$, Ana Luiza de Pádua Pristo ${ }^{4}$, Lauren Silva Maia ${ }^{4}$, \\ Shayene Mara Vaz da Silva ${ }^{4}$, Karoline Alves de Oliveira Marinho ${ }^{5}$, Mariana Braz \\ Pereira $^{50}$, Jeferson Boareto Bertoldo ${ }^{5}$
}

${ }^{I}$ Médico Veterinário, Centro Universitário do Sul de Minas UNIS-MG - Varginha-MG; E-mail: brenomedveterinaria@hotmail.com *Autor para correspondência ${ }^{2}$ Docente do curso de Medicina Veterinária - Centro Universitário do Sul de Minas UNIS-MG;

${ }^{3}$ Professor e Pesquisador Doutor pela Universidade Federal de Lavras - UFLA.

${ }^{4}$ Médica Veterinária - Centro Universitário de Formiga UNIFOR-MG;

${ }^{5}$ Discente do curso de medicina veterinária - Centro Universitário do Sul de Minas UNIS-MG.

RESUMO. A dermatite atópica canina é uma das dermatopatias alérgicas mais comuns em cães que tem origem genética e é de caráter inflamatório crônico, recorrente e demasiadamente pruriginosa. Os animais tornam-se sensibilizados a antígenos ambientais como a poeira doméstica, ácaros e pólen de flores. Em virtude de seu caráter genético, não possui cura clínica, mas é passível de controle. O objetivo deste estudo foi realizar um levantamento das fichas dos atendimentos clínicos de cães diagnosticados com dermatite atópica na Clínica de Medicina Veterinária do Centro Universitário de Formiga, entre os anos de 2010 a 2015. Durante esse período foram realizados 1708 atendimentos e destes, $33(1,9 \%)$ cães foram diagnosticados com dermatite atópica. Neste estudo, $22(66,7 \%)$ dos cães eram de raça definida e quanto ao sexo, $22(66,7 \%)$ fêmeas. Por se tratar de doença altamente pruriginosa, faz-se necessário seu rápido diagnóstico e tratamento para proporcionar melhor qualidade de vida ao animal e seus proprietários.

Palavras chave: atopia, cães, ocorrência

\section{Canine atopy dermatitis: Case study}

ABSTRACT. Canine atopic dermatitis is one of the most common allergic skin diseases in dogs that is genetic and is chronic inflammatory nature, recurrent and too itchy. The animals become sensitized to environmental antigens such as house dust mites and pollen of flowers. Because of its genetic character, has no clinical cure, but is likely to control. The objective of this study was to survey the records of clinical care of dogs diagnosed with atopic dermatitis in Veterinary Clinical Medicine of the Ant University Center between the years 2010 and 2015.During this period were carried out 1708 calls and of these, $33(1.9 \%)$ dogs were diagnosed with atopic dermatitis. In this study, $22(66.7 \%)$ of dogs were mixed breed and the sex, $22(66.7 \%)$ was female. Because it is highly itchy disease, it is necessary to its rapid diagnosis and treatment to provide better quality of life to the animals and their owners.

Keywords: atopy, dogs, occurrence

\section{Dermatite atópica canina: Estúdio de caso}

RESUMEN. La dermatitis atópica canina es una de las dermatopatías alérgicas más comunes en perros que tiene origen genético y es de carácter inflamatorio crónico, recurrente y excesivamente pruriginoso. Los animales se sensibilizan a los antígenos ambientales como el polvo doméstico, los ácaros y el polen de las flores. En virtud de su 
carácter genético, no posee cura clínica, pero es pasible de control. El objetivo de este estudio fue realizar un levantamiento de las fichas de las atenciones clínicas de perros diagnosticados con dermatitis atópica en la Clínica de Medicina Veterinaria del Centro Universitario de Formiga, entre los años 2010 a 2015. se realizaron 1708 atendimientos y de éstos, 33 (1,9\%) perros fueron diagnosticados con dermatitis atópica. En este estudio, $22(66,7 \%)$ de los perros eran de raza definida y en cuanto al sexo, $22(66,7 \%)$ hembras. Por tratarse de una enfermedad altamente pruriginosa, se hace necesario su rápido diagnóstico y tratamiento para proporcionar mejor calidad de vida al animal ya sus propietarios.

Palabras clave: atopia, perros, casuística

\section{Introdução}

A pele é o maior órgão do organismo e é ela quem determina formas, dá características às raças e mantém o recobrimento piloso. Esse órgão possui funções como barreira anatomo-fisiológica entre o ambiente externo e o organismo, sendo imprescindível para a sobrevivência, pois oferece proteção contra perigos físicos, químicos e microbiológicos; possui componentes sensoriais capazes de detectar frio, calor, dor, prurido, toque e pressão; atua na termo regulação do organismo (Scott et al., 1996; Feitosa, 2014; Pinho et al., 2015). A pele é considerada o espelho do organismo, refletindo processos patológicos instalados internamente; reservatório de água, vitaminas, carboidratos, proteínas, ácidos graxos dentre outros eletrólitos; ativação de vitamina $\mathrm{D}$ para ser usada no organismo; confere proteção contra patógenos oportunistas; é uma importante fonte de alimentação para filhotes (através das mamas), entre outros (Scott et al., 1996; Feitosa, 2014; Pinho et al., 2015). As dermatopatias são um dos principais motivos de ida às clinicas veterinárias (Machado et al., 2004). Segundo Feitosa (2014) estima-se que cerca de 30 a $75 \%$ dos atendimentos de pequenos animais estão relacionados com a dermatologia. Os distúrbios dermatológicos são um motivo de preocupação imediata para os proprietários, pois são facilmente perceptíveis (Pinho et al., 2015).

As doenças cutâneas mais frequentemente diagnosticadas no Brasil são as de origem bacteriana, imunopática, endócrina e parasitária (Machado et al., 2004). Dentre essas doenças a dermatite atópica canina se destaca como segundo transtorno cutâneo alérgico mais frequente, sendo menos constante que a dermatite alérgica à picada de pulgas (DAPP) (Zanon et al., 2008).

O objetivo do presente trabalho foi realizar um levantamento de dados dos cães diagnosticados com dermatite atópica na Clínica de Medicina
Veterinária (CLIMVET) do Centro Universitário de Formiga (UNIFOR-MG) do ano de 2010 a 2015.

\section{Relato de caso}

Entre os anos de 2010 a 2015 foram realizados 1708 atendimentos na CLIMVET/UNIFOR-MG. Desse total, 33 (1,9\%) animais foram diagnosticados pelos médicos veterinários responsáveis com Dermatite Atópica Canina (DAC). Esses resultados diferem do estudo realizado por Machado et al. (2004), onde os mesmos isolaram dermatófitos e leveduras da pele de cães com dermatopatias diversas. Esses autores avaliaram 250 animais atendidos no Hospital de Clínicas Veterinárias da Universidade Federal do Rio Grande do Sul, entre os anos de 2000 e 2001, onde encontraram uma prevalência de DAC de $12,8 \%$. Souza et al. (2009) e Gasparetto et al. (2013) realizaram estudos semelhantes, onde objetivaram a prevalência de dermatopatias não neoplásicas em cães dos municípios de Santa Maria/RS e em Cuiabá/MT, onde encontraram uma prevalência de atopia de $16,7 \%$ e $10,5 \%$ respectivamente, apresentando valores bem mais elevados do que o apresentado neste estudo. No entanto, Cardoso et al. (2011) realizaram um trabalho, onde avaliaram 819 fichas de atendimentos clínicos realizados no Serviço de Arquivo do HV - UENP, Bandeirantes, Paraná, entre fevereiro de 2003 a dezembro de 2006, com objetivo de avaliar a prevalência de dermatopatias que mais acometem os cães. Tais autores relataram que 257 animais apresentaram algum distúrbio dermatológico e, dentre esses distúrbios, a dermatite atópica canina aparece com prevalência de $3,9 \%$, resultado esse que mais se aproximou do estudo em questão.

Como justificativa da baixa prevalência de dermatite atópica em cães atendidos na CLIMVET, entre os anos de 2010 a 2015, pode-se relatar a frequência de atendimentos que era 
realizada apenas três vezes por semana de 13 às 17 horas nos cinco primeiros anos avaliados nesse estudo (2010-2014), onde ainda um dia da semana era destinados apenas a atendimentos cirúrgicos, restando, assim, apenas dois dias para atendimentos clínicos.

Todavia, no ano de 2015 a CLIMVET passou a funcionar cinco dias da semana. Deste modo em 2015 foram atendidos 344 animais, onde 15 (4,4\%) cães foram diagnosticados com DAC. A ocorrência da atopia relacionada ao ano e número de atendimentos são observados na tabela 1.

Tabela 1. Ocorrência de dermatite atópica em cães atendidos na Clínica de Medicina Veterinária do Centro Universitário de Formiga - MG, entre 2010 a 2015

\begin{tabular}{lccc}
\hline Ano & $\mathrm{N}^{\circ}$ atendimentos/ano Cães Atópicos & Ocorrência \% \\
\hline 2010 & 319 & 5 & 1,56 \\
2011 & 393 & 3 & 0,76 \\
2012 & 205 & 1 & 0,48 \\
2013 & 166 & 4 & 2,41 \\
2014 & 281 & 5 & 1,78 \\
2015 & 344 & 15 & 4,36 \\
\hline
\end{tabular}

Dos 33 animais incluídos neste estudo, 22 cães $(66,7 \%)$ eram de raças puras, sendo dez cães da raça poodle $(30,3 \%)$, seguido de três animais da raça yorkshire $(9,1 \%)$, dois cães das raças lhasa apso, chow-chow $(6,1 \%)$, e um exemplar da raça beagle, labrador, schnauzer, scott terrier e shih-tzu (3,0\%). Onze cães eram SRD (33,3\%). Esses resultados concordam com Scott et al. (1996) e Zanon et al. (2008), onde afirmaram que a doença tem maior prevalência em animais de raças puras. Esses resultados concordam com o trabalho executado por Vandressen (2014), onde se encontrou 28 cães atópicos, sendo 21 provenientes de raças puras $(75 \%)$ e sete animais mestiços $(25 \%)$.

A frequência dos animais atendidos na CLIMVET/UNIFOR-MG pode ser analisada no gráfico 1.

No entanto, se analisarmos a prevalência de DAC, separada em cada raça (Gráfico 1), observamos que as raças mestiças (SRD) apresentaram maior quantidade do que as outras raças, com índices de 33,3\%, resultados estes que concordam com o trabalho de Diogo et al. (2014), onde foi realizado um estudo retrospectivo com o intuito de submeter 52 cães a biópsias de pele para comparar os achados clínicos laboratoriais de cães com dermatite atópica com os das demais dermatopatias não neoplásicas.

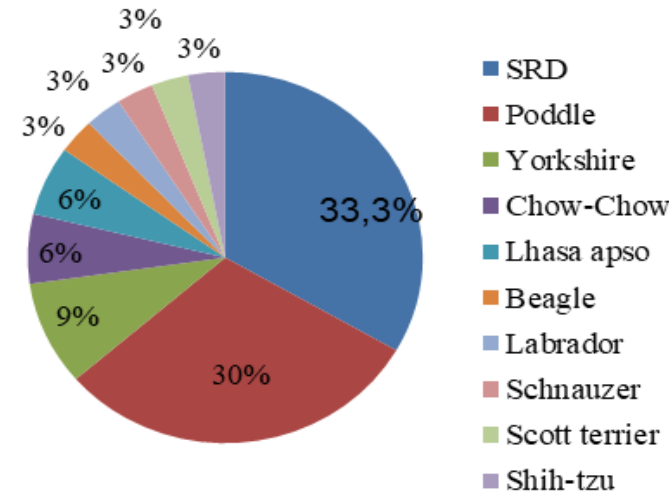

Gráfico 1. Porcentagem de cães atópicos (por raça) atendidos na Clínica de Medicina Veterinária do Centro Universitário de Formiga - MG, entre os anos de 2010 a 2015

Nos resultados das biópsias foram encontradas 23 dermatoses não neoplásicas, onde 11 foram confirmadas como DAC. No entanto, esses autores relataram que 36,6\% dos animais atópicos não tinham padrão racial definido.

Atualmente temos observado cada vez mais ONGs de proteção animal atuando para diminuir o número de animais de rua com isso as mesmas tem promovido campanhas de adoção, fato este que tem aumentado cada vez mais a adoção de animais sem raça definida (SRD) onde os mesmos têm sido considerados membros da família e vivem principalmente dentro de casa, no entanto, existem também programas de informação aos proprietários principalmente sobre a questão reprodutiva de seus animais, incentivando-os a realizarem castrações eletivas, para diminuir as crias indesejáveis, onde as mesmas vão aumentar cada vez mais a miscigenação entre as raças. Fatos esses que possam ter contribuído pelo grande número de animais SRD atópicos, pois se os mesmos se encontrassem nas ruas, muitos morreriam bem antes de desenvolverem os primeiros sintomas da doença.

No presente momento, não existe nenhum estudo confirmatório do surgimento da atopia relacionado com o sexo dos animais em questão. No entanto, o presente estudo observou uma manifestação da DAC em 11 machos e 22 fêmeas.Essas informações foram demonstradas na tabela 2.

Tabela 2. Ocorrência da dermatite atópica associada ao sexo em cães atendidos na Clínica de Medicina Veterinária do Centro Universitário de Formiga - MG, 2010 a 2015

\begin{tabular}{lcc}
\hline Sexo & Cães acometidos & Ocorrência \% \\
\hline Fêmea & 22 & 66,67 \\
Macho & 11 & 33,33 \\
\hline
\end{tabular}


Em um estudo realizado por Neto (2012) visando avaliar a eficácia e segurança da ciclosporina no tratamento de cães atópicos foram utilizados 24 animais, onde se obteve uma ocorrência associada ao sexo idêntica ao estudo em questão16 $(66,7 \%)$ dos animais eram fêmeas e $8(33,3 \%)$ eram machos.

No trabalho realizado por Vandressen (2014) foram encontrados resultados que diferem um pouco, nos percentuais, porém seguem uma mesma proporção de ocorrência sendo, 22 (79\%) fêmeas acometidas e $6(21 \%)$ machos. No entanto, Diogo et al. (2014) não encontraram predisposição sexual nos cães observados em seu estudo, concordando com Farias (2007), que cita, em sua revisão, que não há predisposição sexual. Sendo assim, necessita-se de mais estudos que venham a esclarecer se a atopia, possui alguma predileção sexual.

No presente trabalho a idade em que os animais apresentaram a atopia foi bem variada. No entanto, das 33 fichas avaliadas uma não constava idade do animal. De acordo com Goldston \& Hoskins (1999) foi realizada uma divisão das faixas etárias dos animais da seguinte forma: cães com até um ano de idade, cães entre um a nove anos de idade, e animais com idade igual ou superior a dez anos. Foi observado então que $27(81,8 \%)$ cães apresentaram os sinais da doença ente 1 e nove anos de idade. Resultados estes que discordam de $\underline{\text { Scott et al. }}$ (1996) que afirmam que a atopia acomete geralmente animais entre o primeiro e terceiro ano de vida. Na categoria de cães com até um ano de idade foi encontrado3 $(9,1 \%)$ e na classe igual ou superior a dez anos observamos $2(6,1 \%)$ animais analisados. Concordando assim com Nagelstein (2010) que citou em sua revisão que é incomum o aparecimento da dermatite atópica em cães com menos de 6 meses e mais de 7 anos de idade. Os dados com relação à idade encontram-se na tabela $\underline{3}$.

Tabela 3. Ocorrência de atopia relacionada à idade nos cães atendidos na Clínica de Medicina Veterinária do Centro Universitário de Formiga - MG, entre 2010 a 2015

\begin{tabular}{lcc}
\hline Idade & Cães Acometidos & Ocorrência \% \\
\hline Até 1 ano & 3 & 9,1 \\
1 a 9 anos & 27 & 81,81 \\
Igual ou acima de 10 anos & 2 & 6,06 \\
Não declarada na ficha & 1 & 3,03 \\
\hline
\end{tabular}

Tendo em vista que a poeira domiciliar é o principal alérgeno causador da DAC, neste estudo foi avaliado o local onde os animais vivem, na tentativa de reforçar a teoria de Scott et al. (1996) onde citam que a DA ocorre mais em cães que vivem dentro de casa. No entanto, foram obtidos os seguintes dados: $13(39,4 \%)$ dos cães viviam dentro de casa (in door), 9 (27,3\%) dos animais ficavam fora de casa (out door), $3(9 \%)$ cães tinham hábitos "in door e out door" e $8(24,2 \%)$ animais não continham informações nas fichas sobre o ambiente em que eles viviam. Esses resultados estão demonstrados na tabela 4.

Tabela 4. Ocorrência de atopia relacionada com o ambiente em que os cães viviam

\begin{tabular}{lcc}
\hline Local que o animal vive & Cães Acometidos & Ocorrência \% \\
\hline "In Door" & 13 & $39,4 \%$ \\
"Out Door" & 9 & $27,3 \%$ \\
"In e Out Door" & 3 & $9 \%$ \\
Local não declarado & 8 & $24,2 \%$ \\
\hline
\end{tabular}

Em um trabalho realizado por Assunção (2014), cujo objetivo era avaliar a concentração de alérgenos (ácaros) nos pelos e no ambiente domiciliar de cães atópicos e observar suas relações com as lesões e com o prurido encontrados na atopia foi encontrado que $100 \%$ dos cães avaliados tinham hábitos "in door", resultado esse que difere do apresentado neste estudo, mas reforça a teoria de Scott et al. (1996) deque a atopia ocorre mais em animais "in door".

Muitos sinais clínicos podem ser manifestados devido ao aparecimento da DAC. O prurido é o primeiro sinal clinico a aparecer, no entanto, no presente estudo, ele acometeu $27(81,8 \%)$ dos cães avaliados. Resultado que difere de um estudo realizado por Rondelli et al. (2015), cujo objetivo era avaliar a resposta de cães atópicos a diferentes tratamentos instituídos na rotina clínica do Hospital veterinário da FCAV/ Unesp, em Jaboticabal/SP.

Esses autores encontraram o prurido em $100 \%$ dos cães que participaram do seu estudo. Assim, Diogo et al. (2014), também, observaram prurido em todos os animais utilizados em seu estudo. Esse resultado pode ser explicado, pois algumas fichas não se encontravam totalmente preenchidas, fato que pode ter prejudicado o presente estudo. $\mathrm{O}$ eritema, principalmente de axilas e virilha, a alopecia e a otite também foram relatadas no trabalho de Rondelli et al. (2015) onde os mesmos obtiveram uma ocorrência semelhante.

No presente estudo também foi encontrado outros sinais clínicos como: erupções cutâneas 
(pápulas, pústulas)9 (27,3\%) dos cães avaliados, foliculite, seborreia e lambedura de extremidades em 3 (9\%) dos animais. Lesões oculares foram encontradas em $2(6 \%)$ dos cães e $1(3 \%)$ dos animais apresentou tosse. No entanto, não foram encontrados resultados comparativos dos últimos sinais clínicos apresentados. A ocorrência dos sinais clínicos encontrados nesse estudo é demonstrada na tabela 5 .

No presente estudo também foi avaliado a sazonalidade da DAC, no entanto, essa classificação foi eliminada por falta informações nos prontuários consultados. Na tentativa de amenizar o prurido e melhorar a qualidade de vida dos animais, vários protocolos terapêuticos têm sido usados para controlar a DAC. No presente estudo, o tratamento da DAC foi realizado em $100 \%$ dos casos com a utilização sistêmica de glicocorticóides (Prednisona). Nos casos em que os animais apresentaram otite, foi prescrito tratamento com otosynalar e nos casos onde a foliculite e a seborréia foram encontradas, foi utilizado o peróxido de benzoila $4 \%$ em banhos semanais até o desaparecimento dos sintomas.

Tabela 5. Ocorrência dos sinais clínicos em cães com dermatite atópica, atendidos na Clínica de Medicina Veterinária do Centro Universitário de Formiga - MG, entre 2010 a 2015

\begin{tabular}{lcc}
\hline Sinais clínicos & $\begin{array}{c}\text { Cães } \\
\text { acometidos }\end{array}$ & Ocorrência, \% \\
\hline Prurido & 27 & 81,8 \\
Eritema (Axilas e Virilha) & 16 & 48,5 \\
Erupções cutâneas & 9 & 27,3 \\
Alopecia & 6 & 18,2 \\
Otite & 5 & 15,1 \\
Foliculite/seborreia & 3 & 9 \\
Lambedura de extremidades* & 3 & 9 \\
Lesões oculares & 2 & 6 \\
Tosse & 1 & 3 \\
\hline Nota: Pelos apresentavam-se & pigmentados & (discromia \\
ferruginosa). & &
\end{tabular}

Os resultados desse protocolo terapêutico foram anotados no prontuário de cada animal pelo médico veterinário responsável, onde o mesmo também determinou a percentual de melhora de cada animal. Na tentativa de classificar a melhora dos animais, o autor desse trabalho agrupou o percentual de melhora dos animais da seguinte forma: Melhora de até $50 \%$, de 50 a $80 \%$ e acima de 80 . Esses dados estão expressos no gráfico a seguir.

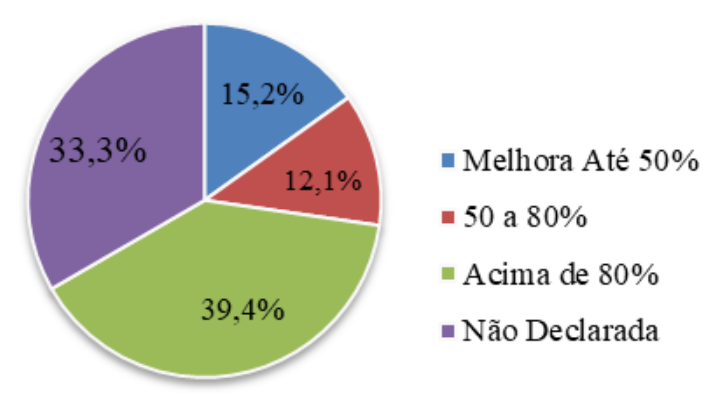

Gráfico 2- Percentual de melhora com a utilização de glicocorticóides sistêmicos, no controle da DAC

No presente estudo, pode-se observar, no gráfico 2, uma resposta satisfatória ao tratamento com glicocorticóides sistêmico, onde 13 (39,4\%) dos cães avaliados apresentaram melhora acima de $80 \%$, também foi observado $5(15,2 \%)$ cães que apresentaram melhoras até $50 \%, 4(12,1 \%)$ dos animais apresentaram melhoras de 50 a $80 \%$ e $11(33,3)$ dos cães não continham em seus prontuários anotações referentes à melhora com $\mathrm{o}$ tratamento. Assim, Rondelli et al. (2015) também obtiveram resultado satisfatório, utilizando a corticoterapia sistêmica, onde $66,7 \%$ dos animais tiveram boa resposta ao tratamento. Os resultados deste estudo concordam com Farias (2007) onde cita em sua revisão que os glicocorticóides sistêmicos possuem uma eficácia por volta 58 a $86 \%$ no controle do prurido.

\section{Considerações finais}

A dermatite atópica canina (DAC) é uma doença comum na clínica de pequenos animais, como citado na literatura, onde causa inúmeros transtornos ao animal e aos proprietários. Entretanto, deve ser diagnosticada e tratada de maneira correta, na tentativa de proporcionar melhor qualidade de vida ao animal e seus proprietários. No presente estudo foi encontrado um percentual de ocorrência de DAC equivalente a $1,9 \%$, em um total de 33 cães.

\section{Referências Bibliográfica}

Assunção, D.L., 2014. Avaliação da concentração de alérgenos provenientes de ácaros na pelagem e na poeira de domicílios de cães (canis lupus familiaris) com dermatite atópica. Escola de Ciências Agrárias e Medicina Veterinária. Pontifícia Universidade Católica do Paraná, São José dos Pinhais, Paraná, 88 p.

Cardoso, M.J.L., Machado, L.H.A., Melussi, M., Zamarian, T.P., Carnielli, C.M., Júnior Ferreira, J.C.M., 2011. Dermatopatias em cães: 
revisão de 257 casos. Archives of Veterinary Science 16, 66-74.

Diogo, J.E., Lima, S.R., Gasparetto, N.D., Almeida, A.B.P.F., Pescador, C.A., Sousa, V.R.F., 2014. Estudo retrospectivo de biópsias de pele: um comparativo da dermatite atópica canina com as demais dermatoses. Acta Veterinaria Brasilica 8, 286-289.

Farias, M.R., 2007. Dermatite atópica canina: da fisiopatologia ao tratamento. Clínica Veterinária 69, 48-62.

Feitosa, F.L.F., 2014. Semiologia veterinária: A arte do diagnóstico. Grupo Gen-Editora Roca Ltda., São Paulo.

Gasparetto, N.D., Trevisan, Y.P.A., Almeida, N.B., Neves, R.C.S.M., Almeida, A.B.P.F., Dutra, V., Colodel, E.M., Sousa, V.R.F., 2013. Prevalência das doenças de pele não neoplásicas em cães no município de Cuiabá, Mato Grosso. Pesquisa Veterinária Brasileira $33,359-362$

Goldston, R.T., Hoskins, J.D., 1999. Geriatria e gerontologia do cão e do gato. Rocca, São Paulo, Brasil.

Machado, M.L.d.S., Appelt, C.E., Ferreiro, L., 2004. Dermatófitos e leveduras isolados da pele de cães com dermatopatias diversas. Acta Scientiae Veterinariae 32, 225-232.

Nagelstein, A.F., 2010. Patogenia da dermatite atópica em cães. Veterinária. Centro Universitário da Grande Dourado, Dourados, Mato Grosso do Sul.

Neto, A. S., 2012. Estudo da Eficácia e Segurança da Ciclosporina no Controle da Dermatite Atópica em Cães. 2012. 116p. Dissertação Mestrado em Ciência Animal, Pontifícia Universidade Católica do Paraná, São José dos Pinhais.
Pinho, R.M., Monzón, M.F., Simões, J., 2015. Dermatologia veterinária em animais de companhia.

Rondelli, M.C.H., Palácios Junior, R.J.G., Oliveira, F.E., Costa, M.T., 2015. Estudo retrospectivo da resposta clínica de cães atópicos a diferentes protocolos terapêuticos. Investigação 14, 45-50.

Scott, D.W., Muller, G.H., Kirk, R.W., 1996. Dermatologia dos pequenos animais. Interlivros, Rio de Janeiro.

Souza, T.M., Fighera, R.A., Schmidt, C., Réquia, A.H., Brum, J.S., Martins, T.B., Barros, C.S.L., 2009. Prevalência das dermatopatias não-tumorais em cães do município de Santa Maria, Rio Grande do Sul (2005-2008). Pesquisa Veterinaria Brasileira 29, 157-162.

Vandressen, G., 2014. Eficácia da ração de soja hidrolisada e da comida caseira com proteína original no controle da dermatite atópica em cães. Escola de Ciências Agrárias e Medicina Veterinária. Pontifícia Universidade Católica do Paraná, São José dos Pinhais, Paraná.

Zanon, J.P., Gomes, L.A., Cury, G.M.M., Teles, T.C., Bicalho, A.P.C.V., 2008. Dermatite atópica canina. Semina: Ciências Agrárias 29, 905-920.

Recebido: 10 Mai., 2018

Aprovado: 18 Jun., 2018

Publicado: 7 Ago., 2018

Licenciamento: Este artigo é publicado na modalidade Acesso Aberto sob a licença Creative Commons Atribuição 4.0 (CC-BY 4.0), a qual permite uso irrestrito, distribuição, reprodução em qualquer meio, desde que o autor e a fonte sejam devidamente creditados. 